\title{
Apresentação da candidatura de Claude Lévi-Strauss à cadeira de Antropologia Social
}

MAURICE MERLEAU-PONTY (TRECHO)

\section{Assembleia dos professores do Collège de France, 15 de março de 1959}

\section{Sr. divetor, meus caros colegas,}

$\int$ OI RECENTEMENTE que a Antropologia Social, entre sociologia e etnologia, conquistou sua autonomia. Os trabalhos do Sr. Claude Lévi-Strauss são crevê-la diante dos senhores, tomarei deles quase tudo, e, para apresentar hoje a candidatura do autor à nova cadeira, praticamente só me resta mostrar de que maneira uma vocação precisa e uma série meditada de trabalhos o levaram ao conjunto de métodos e de ideias cuja importância foi reconhecida ao ser criada a cadeira de Antropologia Social.

O Sr. Lévi-Strauss é formado em Filosofia e até mesmo lecionou durante dois anos após a formatura em liceus do interior. Mas, tão logo teve a oportunidade, partiu para o Brasil e aproveitou essa temporada para visitar, em condições difíceis e mesmo arriscadas, populações do interior. Pertencendo a uma geração muito próxima da dele, posso dizer como essa iniciativa era então original: um universitário de 26 anos precisava ter a mais firme vocação para passar sem transição dos quatro anos de estudos filosóficos a um trabalho de campo que nenhum dos grandes autores da escola francesa, que eu saiba, praticou.

É que já nesse momento, à pergunta "O que é um homem?” ou "Que pode um homem diante da Natureza e dos outros homens?”, o Sr. Lévi-Strauss buscava a resposta, não, à maneira dos filósofos, pelo estudo do exemplar humano disponível no lugar onde se está, mas no encontro efetivo com as variantes extremas do ser humano, tão diversas quanto possível da que somos. Absolutamente diferentes e, no entanto, compreensíveis para nós, contanto que entremos na vida delas, as outras sociedades nos ensinam a reconhecer uma lógica de suas instituições, uma verdade de suas crenças, que sublinham as opções originais da nossa cultura. No intervalo entre elas e as outras possíveis, entrevemos o que se poderia chamar seu projeto fundamental e, ao mesmo tempo, que esse não é senão uma das maneiras de ser homem. É o sentimento de uma humanidade mais diferente e mais próxima de nós do que a sociologia podia fazer supor, sen- 
timento de um estranho parentesco humano, que conservamos dos documentos brasileiros publicados pelo Sr. Lévi-Strauss.

Mas ainda existe aí apenas um sentimento. Ora, o antropólogo não é somente um etnólogo. Essa comunicação que obteve com populações arcaicas, ele quer pensá-la, explicá-la. Fixado em Nova York durante os anos da guerra, o Sr. Lévi-Strauss prepara a obra teórica que publicará ao retornar à França, $A s$ estruturas elementares do parentesco. Perguntar, como ele faz, se a quantidade de regras e instituições relativas ao casamento e ao parentesco são pensáveis como variantes de algumas leis fundamentais é colocar na ordem do saber o problema que o etnólogo encontra na prática, quando busca entrar numa sociedade à qual não pertence. E as soluções, nos dois planos, são paralelas. No plano teórico, o Sr. Lévi-Strauss - antes de justificar a hipótese pela análise dos fatos australianos, chineses, hindus - propõe considerar os sistemas de parentesco como diferentes modos do fenômeno central da troca, característico da sociedade, já que ele institui, pela proibição do incesto, relações de reciprocidade entre os grupos biológicos que fazem parte dela, as alianças sendo doravante impossíveis no interior de cada um desses grupos. Mas, na floresta brasileira, foi esse mesmo fenômeno de troca que permitiu ao etnólogo entrar numa sociedade desconhecida como se aprende uma língua estrangeira pelo método direto. Bem mais prática em sua sociedade de origem, e nessa, a troca permanece em essência a mesma, ela é o fermento de universalidade que torna o homem compreensível para o homem.

No ano seguinte à publicação desse livro, por ocasião de um longo estudo sobre Marcel Mauss, o primeiro a ter uma intuição do papel da troca, o Sr. LéviStrauss dá ao fenômeno todo o seu alcance doutrinal ao identificá-lo com a função simbólica. O que sacraliza a interdição do incesto, criando no primitivo o sentimento do mana, não é senão o mesmo poder humano que sustenta a linguagem: o de considerar um som, um gesto, um ser, não apenas por si mesmo, mas como símbolo de outra coisa, segundo um certo valor de emprego, ficando entendido que o circuito assim aberto será fechado, que essa espécie de abstenção será compensada, que a significação instituída passará a ser definitiva pela conduta simétrica dos outros membros do grupo que respondem e exprimem o que receberam. Essa análise ligava costumes aparentemente irracionais à mesma função que fundamenta entre nós a racionalidade, e cumpria assim a promessa da Antropologia Social, que é abrir um campo comum às culturas, ampliar nossa razão reconduzindo-a às suas fontes e torná-la assim capaz de compreender o que não é ela.

Após esses anos de trabalho teórico, seguindo o ritmo de alternância que é exigido por sua ação, o Sr. Lévi-Strauss retorna em 1950 à experiência etnográfica com uma temporada no Paquistão e na fronteira da Birmânia - depois novamente à teoria com trabalhos relativos à objetividade em antropologia e à noção de modelo. Trata-se sempre de transformar em consciência a experiência direta: a construção de modelos é o método intelectual que nos permite compreender o pressentimento forte e confuso que tivemos do valor emocional dos símbolos no relato mítico ou no desenrolar do ritual. 
Os trabalhos presentes do Sr. Lévi-Strauss e os que ele prepara a seguir procedem evidentemente da mesma inspiração, mas ao mesmo tempo a pesquisa renova-se a si mesma, dá um novo salto sobre suas próprias aquisições. No trabalho de campo na Melanésia, ele espera recolher uma documentação que permitiria, na teoria, uma passagem às estruturas complexas do parentesco - ou seja, àquelas relacionadas, em particular, ao nosso sistema matrimonial. Ora, ele percebe desde agora que isso não será uma simples extensão dos trabalhos precedentes e que lhes dará, ao contrário, um outro alcance. Os sistemas modernos de parentesco - que dão ao condicionamento demográfico, econômico ou psicológico a determinação do cônjuge - deveriam ser definidos, nas perspectivas iniciais, como variantes "mais complexas" da troca. Mas a plena compreensão da troca complexa não deixa intacto o sentido do fenômeno central da troca e possibilita o seu aprofundamento decisivo. O Sr. Lévi-Strauss não pretende assimilar dedutiva e dogmaticamente os sistemas complexos aos sistemas simples. Ao contrário, pensa que não podemos prescindir em relação a eles da abordagem histórica, através da Idade Média, através das instituições indo-europeias e semíticas, e que a análise histórica irá impor a distinção de uma cultura que pró́be absolutamente o incesto - e é a negação simples, direta ou imediata da natureza - e de uma outra cultura - a que está na origem dos sistemas contemporâneos de parentesco - que usa de astúcia com a natureza e às vezes contorna a proibição do incesto. É precisamente esse segundo tipo de cultura que se mostrou capaz de um "corpo a corpo com a natureza", de criar a ciência, a dominação técnica do homem e o que foi chamado de história cumulativa. Portanto, do ponto de vista dos sistemas modernos de parentesco e das sociedades históricas, a troca como negação direta ou imediata da natureza se mostraria como o caso-limite de uma relação mais geral de alteridade. Somente aí será definitivamente decidido o sentido último das primeiras pesquisas do Sr. Lévi-Strauss, a natureza profunda da troca e da função simbólica. No nível das estruturas elementares, as leis da troca, que envolvem completamente a conduta, são suscetíveis de um estudo estático, e o homem, mesmo nem sempre as formulando numa teoria indígena, obedece a elas quase como o átomo observa a lei de distribuição que o define. Na outra extremidade do campo da antropologia, em alguns sistemas complexos, as estruturas explodem e, no que se refere à determinação do cônjuge, se abrem a motivações "históricas". Aqui a troca, a função simbólica e a sociedade não funcionam mais como uma segunda natureza, tão imperiosa como a outra e que a apaga. Cada um é convidado a definir seu próprio sistema de troca; por isso mesmo, as fronteiras das culturas se esfumam e pela primeira vez uma civilização mundial está na ordem do dia. A relação dessa humanidade complexa com a natureza não é nem simples, nem nítida: a psicologia animal e a etologia revelam, na animalidade, não certamente a origem da humanidade, mas esboços, prefigurações parciais e como que caricaturas antecipadas. $\mathrm{O}$ homem e a sociedade não estão exatamente fora da natureza e do biológico: antes distinguem-se dela por reunirem as "apostas" da natureza e por arriscá-las todas 


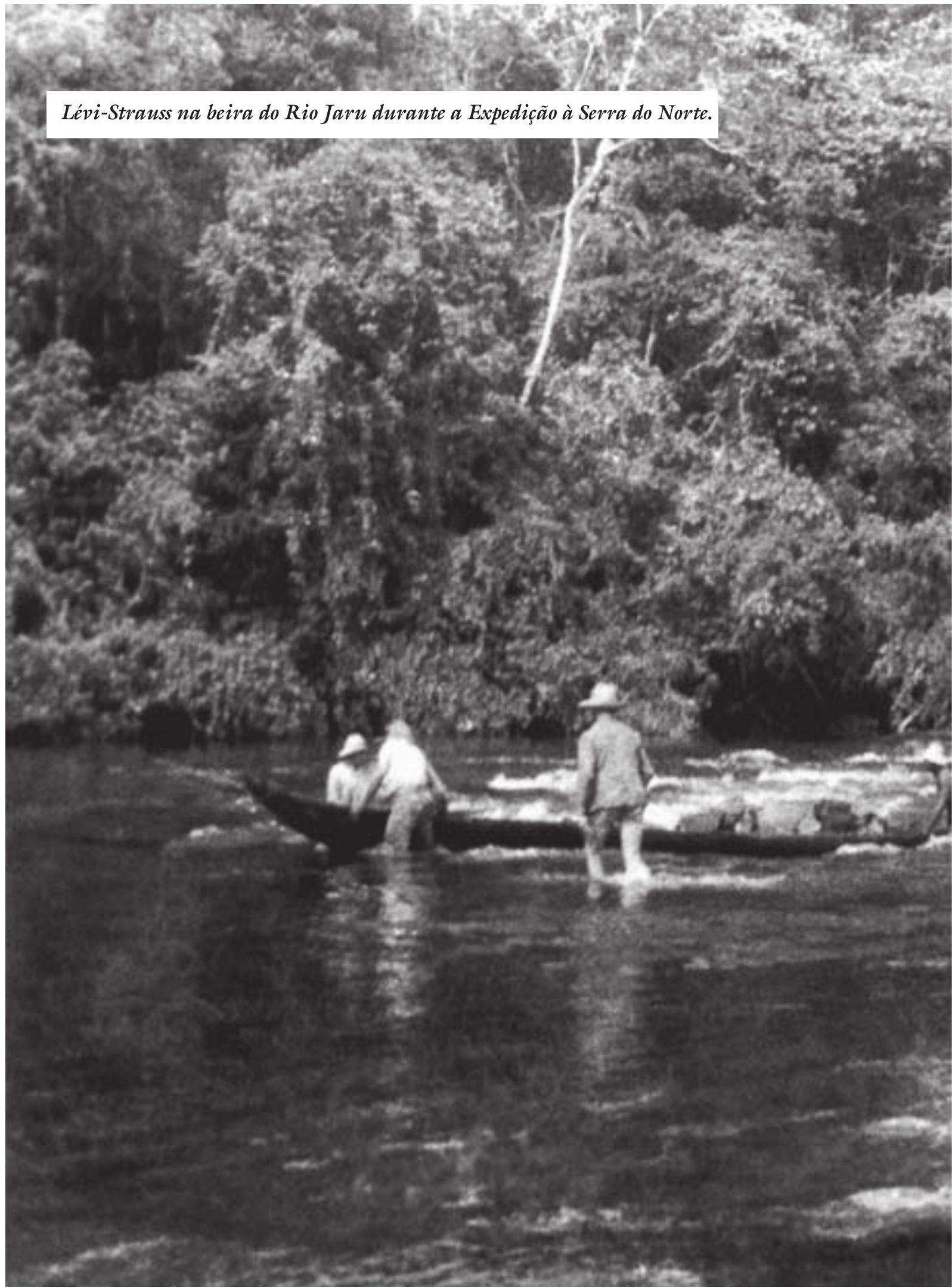


juntas. Essa mudança significa ganhos imensos, possibilidades inteiramente novas, e também perdas que devemos saber avaliar, riscos que começamos a constatar. A troca e a função simbólica perdem sua rigidez, mas também sua beleza hierática; a mitologia e o ritual são substituídos pela razão e pelo método, mas também por um uso muito profano da vida, aliás acompanhado de pequenos mitos compensatórios sem profundidade. É levando em conta tudo isso que a antropologia social se encaminha para um balanço do espírito humano e para uma ideia do que ele é e pode ser...

Assim a pesquisa se alimenta de fatos que lhe parecem de início estranhos; ao progredir, ela adquire novas dimensões, reinterpreta seus primeiros resultados pelas novas pesquisas que eles mesmos suscitaram. A extensão do domínio abrangido e a compreensão precisa dos fatos crescem simultaneamente. Eis aí um sinal dos trabalhos de primeira ordem. Ao propor que o Sr. Claude Lévi-Strauss seja apresentado como primeiro nome à escolha do ministro, tenho consciência de recomendar à atenção dos senhores uma bela, uma grande tentativa intelectual.

Maurice Merleau-Ponty foi um filósofo fenomenólogo francês. Lecionou na Universidade de Lyon e na Universidade de Paris I (Panthéon-Sorbonne). Em 1952 assumiu a Cátedra de Filosofia no Collège de France.

Publicado em Hors Série - La Lettre du Collège de France, Claude Lévi-Strauss - Centième anniversaire, Novembre 2008. Tradução de Paulo Neves. O original em francês - "Présentation de la candidature de Claude Lévi-Strauss à la chaire d'Anthropologie sociale (extrait)" - encontra-se à disposição do leitor no IEA-USP para eventual consulta.

Recebido em 16.7.2009 e aceito em 21.8.2009. 